\title{
Crescimento urbano e áreas de risco no litoral norte de São Paulo
}

\author{
Eduardo Marandola Jr. \\ Cesar Marques ${ }^{* *+}$ \\ Luiz Tiago de Paula \\ Letícia Braga Cassaneli ${ }^{* x+x+\infty}$
}

O crescimento e a expansão urbana trazem, em seu próprio processo constitutivo, riscos e perigos que se expressam pela falta de ajuste e aderência da produção do espaço urbano aos sistemas naturais. Esta situação se agrava quando o próprio sítio é naturalmente frágil, como é o caso das áreas costeiras do litoral norte de São Paulo. Esta região viveu uma de suas décadas de maior crescimento urbano e econômico, no contexto de grandes transformações ligadas à exploração de gás e petróleo, expansão do porto de São Sebastião, mudanças na atividade turística e consolidação da urbanização, especialmente em Caraguatatuba, sede e polo irradiador da maior parte das transformações. Divulgados os dados do Censo Demográfico de 2010, é momento propício para precisar a intensidade e as formas deste crescimento na última década, observado empiricamente, e suas relações com os riscos e vulnerabilidade. Se há uma relação entre urbanização e risco, a tendência é que as intensas mudanças recentes tenham aprofundado e criado novas áreas de risco, com a expansão urbana avançando sobre áreas naturalmente frágeis. O presente estudo procura identificar quem vive ou trabalha nestas áreas, concentrando-se nas novas áreas, a partir de uma compreensão do processo de urbanização no trópico úmido e suas consequências em termos de riscos e vulnerabilidade, com foco nos dados dos Censos Demográficos de 2000 e 2010.

Palavras-chave: Urbanização. Mudança climática. Geografia dos riscos. População e ambiente.

\footnotetext{
* Esse trabalho integra o projeto “Crescimento Urbano, Vulnerabilidade e Adaptação: dimensões sociais e ecológicas das mudanças climáticas no litoral norte de São Paulo" (financiado pela Fapesp, processo n. 2008/58159-7), correspondendo a uma versão revista e ampliada de trabalho apresentado no V Congresso da Asociación Lationoamericana de Población, realizado em Montevidéu, Uruguai, em outubro de 2012.

${ }^{\star *}$ Professor da Faculdade de Ciências Aplicadas, Universidade Estadual de Campinas (eduardo.marandola@fca.unicamp.br).

*** Demógrafo, doutorando em Demografia, Instituto de Filosofia e Ciências Humanas, Universidade Estadual de Campinas (cesar@nepo.unicamp.br).

${ }^{* * * *}$ Geógrafo, bolsista INCT - Mudanças Climáticas, Universidade Estadual de Campinas (luiz.paula@ige.unicamp.br).

***** Graduanda em Geografia, Universidade Estadual de Campinas (leticiacassanellig6@hotmail.com).
} 


\section{Introdução}

A ideia de crescimento é comumente associada à ideia de desenvolvimento, estando ambas relacionadas à evolução positiva. Parte do embate ambiental tem sido questionar tal associação direta, mostrando que nem todo desenvolvimento é positivo, o que não raro tem sido feito destacando-se os efeitos negativos do crescimento sem limites.

Com a consagração, nas últimas décadas, das máximas em torno do desenvolvimento sustentável e da sustentabilidade, têm-se buscado formas de conciliar o que é uma contradição de termos (FLORIANI, 2001): o desenvolvimento pressupõe o crescimento e, por isso, não quer discutir seus limites; o que se busca, portanto, é a ampliação dos limites a partir de otimização de processos, novas tecnologias e inovações que permitam o crescimento a partir da diversificação.

No entanto, os riscos e desastres que têm aumentado e se tornado cada vez mais presentes nas cidades apontam para dificuldades inerentes ao processo de desenvolvimento ligado à urbanização. 0 crescimento e a expansão urbana trazem, em seu próprio processo constitutivo, riscos e perigos que se expressam pela falta de ajuste e aderência da produção do espaço urbano aos sistemas naturais, desde o sítio até ritmos regionais de chuvas, ventos e biodiversidade.

Para Pelling (2003), historicamente as cidades não foram construídas para serem resilientes, nem adequadas à ideia de desenvolvimento sustentável. Mesmo quando se busca uma concepção ecológica das cidades, o autor salienta que há duas principais fraquezas: a incapacidade de sintetizar os imperativos humano e ecológico numa urbanização sustentável; e a incapacidade de equalizar adequadamente a pobreza e a desigualdade social, manifestas na vulnerabilidade da população urbana.

Esta, por outro lado, é comumente responsabilizada pelos desastres ligados às áreas de risco, ou aos problemas urbanos e ambientais de maneira geral. Continuamos enfrentando, até em contextos acadêmicos, a marca de décadas de uma simplificação rasteira que associou o crescimento populacional ao próprio crescimento urbano, levando, por extensão, à responsabilização do crescimento populacional aos próprios males de uma nítida expansão sem limites (HOGAN; MARANDOLA JR.; OJIMA, 2010). Parece óbvio que é pelo crescimento populacional que as cidades continuam crescendo e, por conta disso, os mecanismos de reprodução do espaço urbano e de alocação de novos sítios industriais ou grandes obras de infraestrutura continuam "escondidos" por trás da cortina de fumaça do discurso neomalthusiano em novas roupagens.

Onde e porque as populações urbanas vão morar não é um mero problema locacional, portanto, nem um problema a se resolver no controle do seu crescimento. A situação das populações em área de risco está mais relacionada ao processo de produção da cidade, e dos terrenos que são deixados de lado para tal segmento populacional, do que a uma inadequação na racionalidade de parcelas da população nas escolhas de seus lugares de moradia. Em outras palavras, é um problema de justiça ambiental, de exclusão e segregação (ACSELRAD, 2002; MARANDOLA JR., 2012). 
Esta situação se agrava quando o próprio sítio é naturalmente frágil, como é o caso das áreas costeiras do litoral de São Paulo, especialmente na sua porção norte, onde as escarpas tropicais do Planalto Paulista formam a chamada Serra do Mar, que se aproximam da orla litorânea, entrecortando as planícies oceânicas com íngremes vertentes que se elevam a quase mil metros em menos de um quilômetro (AB'SABER, 2003). As chuvas orográficas que se formam na encosta, fruto da ação das massas de ar Atlântica e Polar, castigam as vertentes de fino solo sobre formações basálticas, o que gera escorregamentos por solapamento, produzindo longas cicatrizes por toda a extensão da escarpa (CRUZ, 1974; MONTEIRO, 1976). As planícies abaixo são propícias para enchentes e possuem uma variabilidade de nível bastante acentuada, o que se dá tanto pelo volume de água que se precipita na base da escarpa quanto pela baixa amplitude topográfica, formando grandes várzeas. Os deltas dos rios que correm da escarpa se abrem em promontórios que são erodidos pela ação das marés, sob um solo arenítico fruto da erosão marinha e fluvial. As planícies também possuem solos arenosos, em processo de contínua sedimentação.

É justamente neste sítio que tem ocorrido um dos mais acentuados processos de expansão e crescimento urbano do Estado de São Paulo: os municípios de Caraguatatuba, São Sebastião e Ubatuba, que ocupam todo o litoral norte, junto com o município de Ilhabela, que fica na ilha de São Sebastião, passaram por uma de suas décadas de maior crescimento urbano e econômico, no contexto de grandes transformações que envolvem a exploração de gás e petróleo, a expansão do porto de São Sebastião, a consolidação de um novo tipo de turismo e da própria urbanização, especialmente em Caraguatatuba, sede e polo irradiador da maior parte das transformações (Figura 1).

Expressão desta opção pela urbanização foi dada no início deste ano, com a aprovação da Região Metropolitana do Vale do Paraíba e do Litoral Norte (RMVPLN), que integra os quatro municípios litorâneos às dinâmicas acima da escarpa, polarizados por São José dos Campos e Taubaté. Assim, a região agrega municípios bastante distintos em termos geográficos, em uma mancha urbana que se estende desde o eixo da Rodovia Presidente Dutra (SP-060), passando pela Rodovia Carvalho Pinto (SP-070), e que está conectada ao litoral pela Estrada dos Tamoios (SP-099). A criação deste novo ente político objetiva viabilizar o desenvolvimento regional e a expansão da urbanização em sua tendência à metropolização. Uma das importantes iniciativas decorrentes de tal projeto de desenvolvimento já se encontra em fase de implantação: a ampliação do eixo rodoviário. Até 2015 será concluída a duplicação da Rodovia Tamoios - trecho planalto $(64 \mathrm{~km}$ de rodovia entre Caraguatatuba e São José dos Campos), trecho serra (aproximadamente $17 \mathrm{~km}$ ) - e construído um novo contorno entre Caraguatatuba e Ubatuba ( $42 \mathrm{~km}$ de novas estradas). Assim, consolidar-se-ia o modelo logístico rodoviário, visando a demanda do fluxo bidirecional de cargas, do movimento do polo de gás/petróleo e caminhões associados ao funcionamento do porto (DERSA, 2011).

Esta contínua expansão urbana regional sobre um sítio naturalmente frágil - que já viveu situações de desastres de alta consequência (CASTRO; MELLO, 2012) - cria situações ambientais potencialmente estressantes. No cenário atual de mudanças ambientais e 
climáticas globais, as regiões litorâneas são especialmente atingidas, e o litoral norte paulista não está preparado, nem em termos de diagnósticos (conhecimento sobre os problemas) nem em termos da legislação e capacidade de resposta, para enfrentar a vulnerabilidade crescente (FRANCINE JR.; GALLO JR.; OLIVATO, 2009). Há necessidade de entender tanto as dinâmicas biofísicas dos fenômenos quanto a população afetada (CARMO; NUNES, 2008) e as estratégias, implicações e consequências para a governança do risco (DI GIULIO; FERREIRA, 2012), o que envolve várias dimensões da realidade urbana na região.

FIGURA 1

Litoral norte paulista - 2010

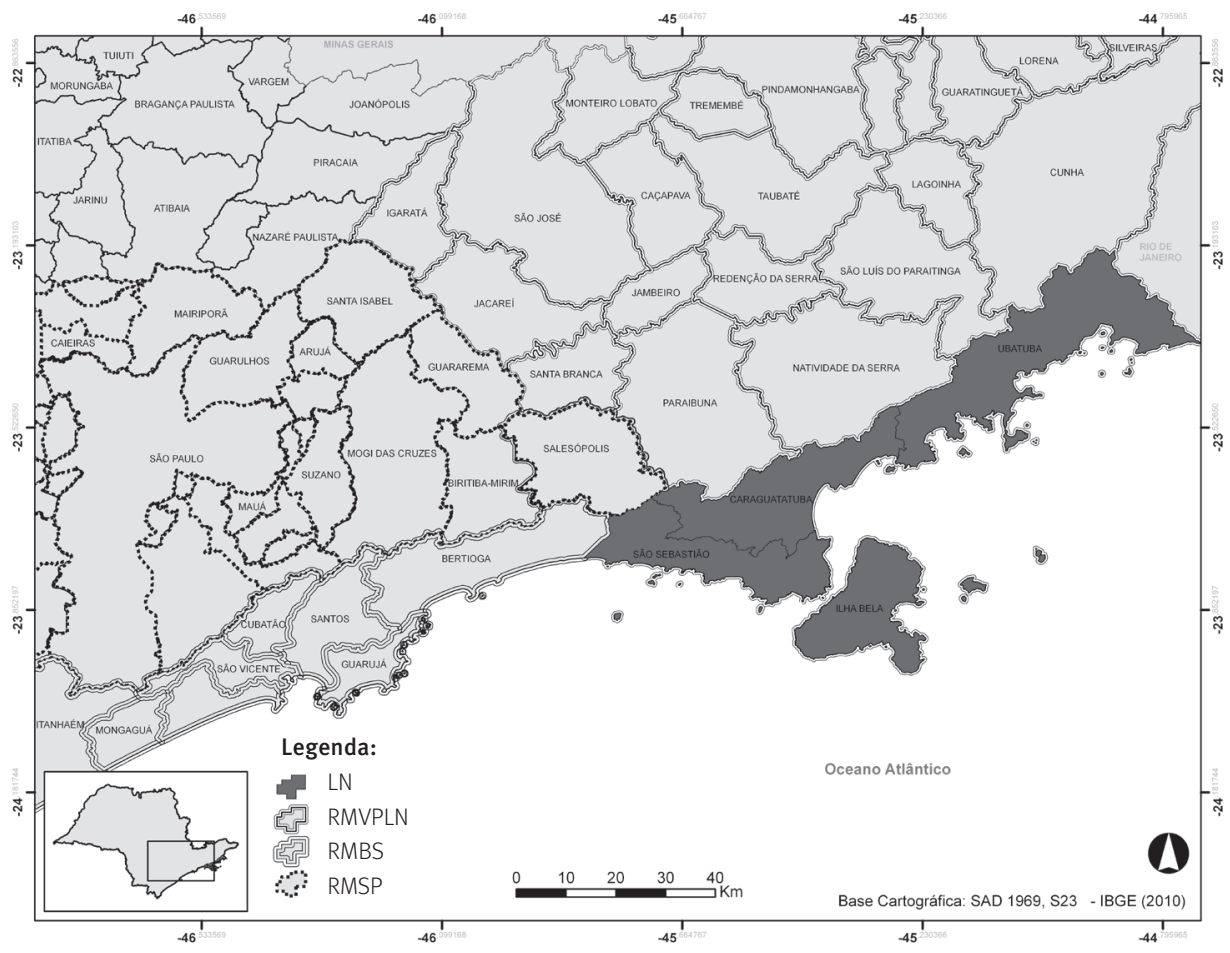

Fonte: Base cartográfica SAD 1969, S23 - IBGE (2010).

Com a divulgação dos dados do Censo 2010, o momento é propício para precisar a intensidade e as formas deste crescimento na última década, observado empiricamente, e suas consequências em termos de riscos e da vulnerabilidade. Se há uma relação entre urbanização e risco, então a tendência é que o crescimento da última década tenha acentuado antigas áreas de risco, além de potencialmente criado outras, já que a expansão urbana, sem o devido ajuste aos sistemas biofísicos, tenda a avançar sobre áreas frágeis como encostas e fundos de vale. 
Neste sentido, seguindo a sugestão de Hardoy e Pandiella (2009), que propuseram seis aspectos da vulnerabilidade fundamentais para uma perspectiva social em termos da América Latina, o presente estudo procura identificar quem vive ou trabalha em áreas expostas diretamente a perigos, concentrando-se nas novas áreas geradas pelos processos recentes da expansão urbana da última década. Para tanto, partiu-se de uma compreensão do processo de urbanização no trópico úmido e suas consequências em termos de riscos e vulnerabilidade, com foco nos dados comparativos dos Censos de 2000 e 2010 para mostrar a íntima relação entre o crescimento urbano e o aumento das áreas de risco, o que aponta para urbanização de risco, sem promoção de resiliência.

\section{Urbanização e risco no trópico úmido}

Ao se falar em processo de urbanização é necessário considerar que essas novas dinâmicas estão vinculadas a novos aspectos de transformações socioeconômicas e espaciais das cidades, a novas dinâmicas populacionais, a mudanças no mercado de trabalho, a desigualdades regionais e à nova ocupação do território (SCHVASBEG, 2003). Grandes investimentos são, na maior parte das vezes, o vetor que impulsiona o desenvolvimento urbano de uma região. A chegada de obras que envolvem grandes investimentos movimenta a economia e torna a região um polo de atração populacional e de outros setores da economia que esperam e ajudam a promover o desenvolvimento econômico e de infraestrutura.

A ocupação e o desenvolvimento urbano do litoral norte paulista foram marcados por estes impulsos que grandes obras produziram na região. O primeiro grande empreendimento foi a implantação do Terminal Marítimo Almirante Barroso (Tebar) em São Sebastião, associado à exploração de seu porto. Além disso, a construção da Rodovia Tamoios, que liga o planalto ao litoral, e especialmente a construção e asfaltamento da Rodovia Rio-Santos, que estabeleceu uma ligação perene por terra de todo o litoral norte, foram os principais vetores que induziram o desenvolvimento de uma região de aldeias e vilarejos tradicionais, para uma área urbanizada voltada para exploração turística (LUCHIARI, 1999).

Uma nova onda de investimentos, iniciada há aproximadamente uma década, tem introduzido outra série de modificações no padrão de uso e ocupação do solo, do perfil da urbanização e, especialmente, dos impactos e riscos ambientais gerados por tal processo. O desenvolvimento nacional na área petrolífera, a descoberta da camada de pré-sal, a construção da Unidade de Tratamento de Gás Monteiro Lobato de Caraguatatuba (UTGCA) e a ampliação do porto de São Sebastião fizeram da região um polo atrativo para uma grande quantidade de trabalhadores (ROCHA, 2011). A região foi potencializada como atrativa a migrantes, promovendo a continuidade do alto ritmo de crescimento populacional, sem que as mudanças estruturais acompanhassem as necessidades locais com a mesma velocidade. Essa nova realidade soma-se aos já insuficientes serviços urbanos prestados no litoral. 0 saneamento básico é um dos pontos críticos. Historicamente precária, a rede coletora de esgoto cobria, em 2003, apenas 25\% dos domicílios urbanos em Caraguatatuba, 3\% em 
Ilhabela, 29\% em São Sebastião e 17\% em Ubatuba, segundo a Pesquisa Nacional de Saneamento Básico.

O conflito entre urbanização, desenvolvimento e ambiente se manifesta no aumento de riscos, seja pela ocupação de áreas frágeis biofisicamente, o que produz áreas de risco no tecido urbano, seja na produção de vulnerabilidades a camadas cada vez mais significativas da população. Isso se manifesta na rápida expansão da mancha urbana sem a infraestrutura básica para atender às necessidades da população, o que aumenta a exposição aos riscos e perigos ambientais. Essa região é caracterizada pela reduzida extensão de planície costeira, destinada à construção habitacional, levando grande contingente populacional a ocupar áreas de várzeas com baixa ou nenhuma declividade, ou mesmo áreas das intensas chuvas orográficas, gerando novas áreas de risco; tais como encostas de morros, áreas de preservação ambiental e áreas junto ao leito de rios e mais próximas da costa.

As consequências do processo inadequado de crescimento são a falta de condições sanitárias mínimas; ausência de serviços indispensáveis à vida das pessoas nas cidades; ocupação de áreas inadequadas; destruição de recursos de valor ecológico; poluição do meio ambiente; habitações em condições precárias de vida. (VILLASCHI, 2003, p. 166)

Mas a origem do problema não é o crescimento populacional. É a população que é exposta aos riscos das transformações do modelo de desenvolvimento urbano em um ambiente naturalmente frágil. A vulnerabilidade "[...] revela as fragilidades e as capacidades das pessoas e sistemas de passar pela experiência do perigo" (MARANDOLA JR., 2009, p. 37). O fator demográfico assume aqui um papel duplo, sendo o homem capaz de influenciar o ambiente, mas também de sofrer forte influência deste sobre si, assumindo assim um papel de "via de mão dupla $P \leftrightarrow A$, sem prevalência de um polo sobre outro" (MARANDOLA JR.; HOGAN, 2009, p. 163).

Entre as possíveis mudanças ambientais, a mudança climática é um dos processos mais importantes em discussão nos últimos anos e, dadas as interfaces terra-mar, as cidades litorâneas são de espacial interesse. Além disso, é necessário atentar que as mudanças climáticas ocorreram em cidades já carregadas de conflitos e questões a resolver. “E considerando o acúmulo de problemas ambientais e o atraso na criação de uma infraestrutura ambiental vis-à-vis o crescimento de cidades, elas não estão preparadas hoje para a mudança climática" (HOGAN, 2009, p. 15). Por estar dentro da faixa tropical e sobre influência direta do domínio climático Tropical Atlântico, essa região tende a sofrer mais intensamente os episódios climáticos e ambientais que se manifestarão na forma de riscos e perigos específicos, como elevação do nível do mar, erosão marinha, salinização dos deltas de rios, entre outros (CARMO; MARQUES, 2009).

A localização geográfica, a geomorfologia local, as características geológicas, o clima e a vegetação predominantes são fatores que compõem a vulnerabilidade do lugar, expondo a população a determinados riscos. Uma das características mais importantes e determinantes do litoral norte de São Paulo é a proximidade da Serra do Mar com a encosta oceânica. "Toda 
linha de costa do litoral Norte é acompanhada de perto pelas escarpas da serra do Mar, em setores que mudam de direção de acordo com sua maior ou menor aproximação da Serra até o oceano" (CRUZ, 1974, p. 34).

As variações altimétricas, a proximidade com a costa oceânica, a grande declividade das escarpas, o relevo distinto e o sistema de falhamentos locais (constituído geomorfologicamente porvárias deformações e rupturas) indicam a alta suscetibilidade regional a eventos extremos de deslocamento gravitacional de massas, escorregamentos e intensidade fluvial. "Um dos aspectos mais importantes da compartimentação geomorfológica e das flutuações climáticas quaternárias diz respeito ao papel desempenhado pela escarpa da Serra do Mar, de vez que ela teria sido capaz de assegurar um teor mínimo de umidade e precipitações" (MONTEIRO, 1976, p. 22). Considerando-se a pouca extensão territorial da planície costeira, sendo a maior parte na cidade de Caraguatatuba, e a maneira intensa como as quatro cidades do litoral norte paulista vêm se expandindo, a malha urbana faz com que seja cada vez mais evidente a alocação da população em áreas de risco, principalmente próximo a encostas íngremes da Serra do Mar e a leitos fluviais. Algumas localidades do litoral norte paulista recebem o nome de litoral afogado, por ter o mergulho direto da Serra do Mar no oceano.

As escarpas da Serra do Mar no litoral Norte muitas vezes mergulham no oceano, descendo em patamares por meio de seus esporões. Pequenas praias ocupam os espaços entre eles. À retaguarda delas, desenvolvem-se baixadas, pequenas e pouco largas, com uma drenagem curta que, descendo das encostas escarpadas, por elas divaga até o mar (CRUZ, 1974, p. 49).

A posição intertropical, o relevo e a presença da Mata Atlântica proporcionam características climáticas à região peculiares que expõem a população, seja ela residente ou não, a eventos extremos. $\mathrm{O}$ alto índice de radiação solar, conjuntamente com a topografia da Serra do Mar e a influência oceânica, favorece a ocorrência de chuvas do tipo orográfica, expondo a região a um intenso e importante fluxo de umidade. Segundo Conti (2010), esse alto índice de concentração energética registrado nas regiões intertropicais é imprescindivel para compreensão da influência da tropicalidade sobre as características morfoclimáticas da região.

Em toda a faixa intertropical o sol está muito presente o ano todo, fazendo uma "varredura, a cada solstício ou intervalo de seis meses, entre um trópico e outro, tornando-a privilegiada em relação ao recebimento da radiação solar, dotando-a por isso mesmo, de um excedente energético muito significativo sobre o restante do planeta. [...] Essa importante concentração energética é dado preliminar para o entendimento da natureza tropical, pois daí derivam importantes consequências, como, por exemplo, sua riquíssima biodiversidade e as características superlativas de sua natureza (CONTI, 2010, p. 50).

Como característica do tipo climático predominante, tropical úmido de altitude, as chuvas são algo constante ao longo de todo o ano na região, intensificando-se no verão, nos meses de dezembro a março. Esse período do ano, em toda a região litorânea, coincide com as atividades turísticas (veraneio), o que acaba por causar maior pressão sobre o meio ambiente já sobrecarregado, podendo provocar grandes desastres naturais vinculados a fenômenos de origem hidrometeorológica, como inundação, escorregamento e deslizamento de massas. 0 
aumento populacional registrado nesse período turístico faz com que seja crescente também o número de pessoas expostas aos riscos ambientais, não sendo exposição necessariamente relacionada com o status social da população.

Apesar da sua localização dentro da região tropical do globo, a vegetação predominante no litoral norte também está relacionada com as características das manchas do solo da região. Por sua característica, a floresta pluvial atlântica é dotada de extrema importância em relação aos problemas de deslizamentos das encostas na região do litoral norte paulista. A mata atlântica age como um interceptor das chuvas e é capaz de absorver o excedente pluvial, o que dá à vegetação o papel de agente protetor do solo, aparecendo assim como uma medida eficaz de prevenção a incidentes catastróficos na região.

À altura do estado de São Paulo, as matas atlânticas penetram por todos os planaltos interiores, com fortes irregularidades na depressão periférica central do território, onde ocorre um espaçado mosaico de cerrados, matas em faixas de calcários e terras roxas oriundas da decomposição de basalto. Não são os climas tropicais mesotérmicos dos planaltos que garantem a presença de florestas biodiversas, mas, sim, a riqueza de algumas grandes manchas de solos ricos e influencia orográfica na Serra do Mar, rebordos sul-orientais e ocidentais da Mantiqueira e escarpas de cuestas areníticos-basálticos do interior. (AB'SÁBER, 2007, p. 49-50)

É notável que os benefícios proporcionados pela urbanização sejam muitas vezes reduzidos quando comparados com as consequências desse processo. A lógica de exploração dos recursos naturais expõe grande parte da população a perigos ambientais. "A imposição urbana e a marcha da industrialização impõem novas exigências e criam novas formas de uso do espaço, configurando novos problemas" (MONTEIRO, 1976, p. 46). Na maior parte das vezes, a população menos favorecida economicamente é a que mais sofre com os incidentes ambientais (HOGAN, 1993). As cidades do litoral norte paulista, principalmente São Sebastião e Caraguatatuba, têm crescido e se expandido de maneira intensa nos últimos anos, porém as infraestruturas básicas não vêm acompanhando esse mesmo ritmo de crescimento. Isso coloca a população em alerta quanto ao perigo de ocorrerem, na região, catástrofes intensas como a tromba d’água registrada em 1967.

\section{Crescimento urbano e ocupação de áreas de risco (2000-2010)}

O padrão de urbanização do litoral norte de São Paulo, na década de 2000, está associado às crises dos anos 1980 e 1990, em função da ruptura entre políticas urbanas e planejamento territorial dessas cidades. Nos principais centros urbanos do Estado, a década de 2000 foi marcada pela continuidade do crescimento urbano desordenado, reafirmando-se seja por grandes empreendimentos imobiliários que envolviam condomínios residenciais, seja por extensas periferias que se desenvolviam sobre as áreas de expansão urbana mais carentes.

O caso do litoral norte tem sua peculiaridade devido ao próprio sítio onde este processo de ocupação ocorre, como debatido. As áreas urbanas pretéritas e consolidadas estão limitadas às planícies costeiras, que se formaram entre a linha da orla e a escarpa da Serra 
do Mar. Esse elemento natural limitante à expansão urbana implicou, até atualmente, dois caminhos quanto ao crescimento dessas cidades: o primeiro é a refuncionalização das áreas planas já existentes; e o segundo refere-se à possibilidade de ocupação de áreas limítrofes entre a planície e a escarpa.

Quanto ao primeiro caminho, tem-se o exemplo do Tebar, no município de São Sebastião, construído no início dos anos 1960. Para sua construção, desocuparam-se áreas rurais, compostas de fazendas, roças e chácaras, mas que já desenhavam relações essencialmente urbanas. Sua própria instalação potencializou a migração de contingente populacional para trabalhar na obra. Atualmente, este terminal, que foi o centro das atenções quanto a perigos relacionados a vazamentos de óleo nos cursos d'água, contaminação de solo, incêndios e explosões, é circundado por bairros urbanos, como Vila Amélia, Topolândia e Porto Grande, o que reforça a atenção quanto à exposição a riscos desses lugares (MODESTO, 2011; MODESTO; MARANDOLA JR., 2012).

Em relação ao segundo, a situação não é menos alarmante. Entre alguns bairros que avançam o sopé de taludes nessas cidades litorâneas, estão as áreas de assentamento urbano precário, caracterizadas pela ausência de infraestrutura, como drenagem, pavimentação e saneamento, e de serviços básicos como a presença de coleta de lixo, redes elétricas, hidráulicas, etc. Esta combinação de fatores negativos soma-se aos riscos de ordem natural, como áreas de enchentes nas planícies de inundação naturais dos rios, ou regiões ocupadas próximas às áreas de instabilidade estrutural das encostas, podendo afetar diretamente a segurança dessas moradias. Tal situação, no entanto, não é exclusiva da região. No próprio litoral de São Paulo, trabalhos já realizados previamente indicaram a composição sociodemográfica das áreas de risco e suas implicações em termos das dinâmicas de mudança social e ambiental (MARQUES, 2010). Estes problemas existentes não são resultado direto do aumento da população urbana. Trata-se da ausência de políticas públicas que articulem o desenvolvimento deste processo. 0 desafio de planejar e pensar políticas que suprem as demandas requeridas pelo "crescimento" aumenta à medida que as taxas de expansão populacional relativamente se reduzem (Tabela 1) - mas permanecem entre as maiores do Estado de São Paulo - e os graus de urbanização também (Tabela 2) (CARMO; MARQUES; MIRANDA, 2012).

TABELA 1

População urbana e taxas de crescimento da população urbana Municípios do litoral norte paulista-1970-2010

\begin{tabular}{|c|c|c|c|c|c|c|c|c|c|}
\hline \multirow[b]{2}{*}{ Municípios } & \multicolumn{5}{|c|}{ População urbana } & \multicolumn{4}{|c|}{ Taxas de crescimento (\% a.a.) } \\
\hline & 1970 & 1980 & 1991 & 2000 & 2010 & $\begin{array}{c}1970 / \\
1980\end{array}$ & $\begin{array}{c}1980 / \\
1991\end{array}$ & $\begin{array}{l}1991 / \\
2000\end{array}$ & $\begin{array}{c}2000 / \\
2010\end{array}$ \\
\hline Ubatuba & 9.083 & 24.673 & 46.333 & 65.195 & 76.907 & 10,51 & 5,90 & 3,87 & 1,67 \\
\hline Caraguatatuba & 13.121 & 33.215 & 52.729 & 75.251 & 96.673 & 9,73 & 4,29 & 4,03 & 2,62 \\
\hline Ilhabela & 5.434 & 7.571 & 13.286 & 20.589 & 28.002 & 3,37 & 5,25 & 4,99 & 3,12 \\
\hline São Sebastião & 11.259 & 18.598 & 33.702 & 57.452 & 73.109 & 5,15 & 5,55 & 6,11 & 2,42 \\
\hline Litoral norte & 38.897 & 84.057 & 146.050 & 218.487 & 274.691 & 8,01 & 5,15 & 4,58 & 2,34 \\
\hline
\end{tabular}

Fonte: IBGE. Sistema IBGE de Recuperação Automática - Sidra. Dados atualizados em 02/2011. 
TABELA 2

Graus de urbanização

Municípios do litoral norte paulista -1970-2010

\begin{tabular}{lccccc}
\multicolumn{1}{c}{ Municípios } & $\mathbf{1 9 7 0}$ & $\mathbf{1 9 8 0}$ & $\mathbf{1 9 9 1}$ & $\mathbf{2 0 0 0}$ & $\mathbf{2 0 1 0}$ \\
\hline Ubatuba & $\mathbf{5 9 , 7 4}$ & $\mathbf{9 0 , 9 1}$ & $\mathbf{9 7 , 7 5}$ & 97,51 & 97,60 \\
Caraguatatuba & $\mathbf{8 7 , 0 5}$ & 98,26 & 99,72 & 95,35 & 95,87 \\
Ilhabela & 95,22 & 97,06 & 98,14 & 98,81 & 99,31 \\
São Sebastião & 93,70 & 97,90 & 99,45 & 98,99 & 98,87 \\
Litoral norte & $\mathbf{8 1 , 0 4}$ & $\mathbf{9 5 , 8 0}$ & $\mathbf{9 8 , 8 8}$ & $\mathbf{9 7 , 2 5}$ & $\mathbf{9 8 , 6 4}$ \\
\hline
\end{tabular}

Fonte: IBGE. Censos Demográficos de 1970 a 2010.

A maior parte do crescimento populacional ocorreu nas áreas urbanas. Em Caraguatatuba e Ilhabela, as taxas de crescimento da população urbana são maiores do que aquelas registradas para o total do litoral norte. De certo modo, o crescimento mais intenso ainda pode ser explicado por uma população que é relativamente pequena, em que o impacto de dezenas de milhares de pessoas é muito maior quando comparado ao crescimento absoluto em megacidades como São Paulo. No entanto, os fatores de atração da região têm mostrado um claro vigor no que tange à urbanização e ao crescimento populacional. Enquanto o litoral como um todo cresce 1,33\% a.a. (valor superior aos observados para o Estado de São Paulo e Brasil), os municípios do litoral norte apresentam taxas de 2,34\% a.a. na última década.

Por outro lado, a natureza do urbano em tais áreas está em transformação. De maneira geral, a urbanização da costa brasileira é amplamente heterogênea e atua com lógicas distintas nesses espaços. A face litorânea da urbanização do macroeixo São Paulo-Rio de Janeiro, com a crescente conurbação de municípios desde o sul da Baixada Santista até o norte da Baía de Guanabara, remete a um processo amplo de mudança social (MORAES, 2007). A intensificação dos projetos apoiados pelo governo na esfera da produção energética e na infraestrutura de transporte revela a importância estratégica de tais lugares, que ao longo da última década se diversificaram economicamente, tornando-se menos dependentes do turismo.

Em Caraguatatuba, o PIB da indústria já corresponde a 16,82\% do PIB municipal, sendo o município do litoral norte com a maior participação da indústria na composição da economia. Em relação ao total do litoral, os valores maiores ainda se concentram na Baixada Santista, que possui um polo portuário e industrial já bem consolidado (CARMO; MARQUES; MIRANDA, 2012).

Embora seja um retrato incompleto de tais transformações, a partir de dados censitários é possivel observar algumas dimensões e consequências desses processos. Com eles, foram captados elementos da dinâmica imobiliária da cidade, analisando-se as formas de ocupação do domicílio (se os domicílios são próprios, alugados ou cedidos), o que ajuda a entender os impactos deste crescimento, em termos do tipo de moradia e de composição das habitações.

A região, que historicamente possui as maiores porcentagens de domicílios ocasionais na composição total de domicílios, intimamente relacionados ao turismo baseado na segunda 
residência, está com porcentagens decrescentes desse tipo de ocupação. Nesse processo os locais destinados à moradia fixa têm crescido de forma mais intensa do que aqueles para uso ocasional, indicando mudanças nas funções que os territórios da região assumem neste novo contexto de metropolização.

Entre 1991 e 2010, a grande maioria dos municípios do litoral apresentou queda no ritmo do crescimento domiciliar (Tabela 4). O litoral sul foi a exceção, com um leve acréscimo (3,9\% no período) no ritmo da construção das unidades residenciais. São Sebastião teve a redução mais intensa, com 55\% para o período. Caraguatatuba e Baixada Santista também tiveram queda superior a 50\%. No entanto, é necessário avaliar os componentes dessa diminuição. Os domicílios ocupados e os não ocupados apresentaram índices bastante diferenciados. As maiores taxas de crescimento de unidades ocupadas estão no litoral norte, enquanto no litoral sul encontram-se as maiores taxas para os domicílios não ocupados. Na Baixada Santista houve uma inversão significativa entre os períodos. Se até 2000 as unidades não ocupadas cresciam mais intensamente do que as ocupadas, no período posterior os domicílios para uso permanente aumentaram a taxas três vezes superiores às verificadas em domicílios não ocupados.

Especificamente em Caraguatatuba, entre 1991 e 2000, o crescimento das unidades ocupadas foi 58\% superior ao daquelas não ocupadas. No período posterior (2000-2010), o aumento dos domicílios ocupados foi de praticamente quatro vezes o verificado para os não ocupados. Essa foi a maior diferença entre todas as unidades territoriais observadas. Considerando o litoral de todo o Estado, somente Praia Grande (na Baixada Santista) apresentou uma razão superior a essa, com um índice de 4,3 vezes.

TABELA 3

Domicílios particulares não ocupados de uso ocasional e vagos Litoral do Estado de São Paulo - 2000-2010

\begin{tabular}{|c|c|c|c|c|c|c|c|c|}
\hline \multirow{3}{*}{$\begin{array}{l}\text { Unidade } \\
\text { territorial }\end{array}$} & \multicolumn{4}{|c|}{2000} & \multicolumn{4}{|c|}{2010} \\
\hline & \multicolumn{2}{|c|}{$\begin{array}{c}\text { Domicílios } \\
\text { particulares não } \\
\text { ocupados de } \\
\text { uso ocasional }\end{array}$} & \multirow{2}{*}{$\begin{array}{c}\text { Domicílios } \\
\text { particulares } \\
\text { não } \\
\text { ocupados } \\
\text { vagos }\end{array}$} & \multirow[t]{2}{*}{$\begin{array}{c}\text { Total de } \\
\text { domicílios } \\
\text { particulares }\end{array}$} & \multicolumn{2}{|c|}{$\begin{array}{c}\text { Domicílios } \\
\text { particulares não } \\
\text { ocupados de } \\
\text { uso ocasional }\end{array}$} & \multirow{2}{*}{$\begin{array}{c}\text { Domicílios } \\
\text { particulares } \\
\text { não } \\
\text { ocupados } \\
\text { vagos }\end{array}$} & \multirow[t]{2}{*}{$\begin{array}{c}\text { Total de } \\
\text { domicílios } \\
\text { particulares }\end{array}$} \\
\hline & N. abs. & $\%$ & & & N. abs. & $\%$ & & \\
\hline Ubatuba & 23.997 & 52,10 & 3.597 & 46.057 & 30.036 & 50,30 & 4.538 & 59.705 \\
\hline Caraguatatuba & 24.795 & 47,57 & 4.857 & 51.972 & 27.902 & 43,20 & 4.680 & 64.578 \\
\hline Ilhabela & 3.146 & 32,08 & 761 & 9.714 & 4.130 & 28,40 & 1.366 & 14.540 \\
\hline São Sebastião & 13.713 & 41,48 & 2.710 & 32.792 & 16.628 & 38,70 & 2.777 & 43.013 \\
\hline Litoral norte & 65.651 & 46,72 & 11.925 & 140.535 & 78.696 & 43,28 & 13.361 & 181.836 \\
\hline Baixada Santista & 252.514 & 33,95 & 61.314 & 743.712 & 288.946 & 33,24 & 51.584 & 869.209 \\
\hline Litoral sul & 7.691 & 34,85 & 1.964 & 22.066 & 11.663 & 38,07 & 3.053 & 30.639 \\
\hline $\begin{array}{l}\text { Total do litoral } \\
\text { SP }\end{array}$ & 325.856 & 35,95 & 75.203 & 906.313 & 379.305 & 35,07 & 67.998 & 1.081 .684 \\
\hline
\end{tabular}

Fonte: IBGE. Censos Demográficos de 1991-2010. 
TABELA 4

Taxas de crescimento dos domicílios particulares, por condição de uso dos domicílios Litoral do Estado de São Paulo - 1991-2010

\begin{tabular}{|c|c|c|c|c|c|c|c|}
\hline \multirow{2}{*}{$\begin{array}{l}\text { Unidade } \\
\text { territorial }\end{array}$} & \multicolumn{3}{|c|}{ 1991/2000 (\% a.a.) } & \multicolumn{4}{|c|}{$2000 / 2010$ (\% a.a.) } \\
\hline & Total & Ocupados & $\begin{array}{c}\text { Não } \\
\text { ocupados }\end{array}$ & Total & Ocupados & $\begin{array}{c}\text { Não } \\
\text { ocupados }\end{array}$ & $\begin{array}{c}\text { Uso } \\
\text { ocasional }\end{array}$ \\
\hline Ubatuba & 4,69 & 5,07 & 4,46 & 2,64 & 3,18 & 2,25 & 2,27 \\
\hline Caraguatatuba & 4,71 & 6,05 & 3,82 & 2,19 & 3,68 & 0,94 & 1,19 \\
\hline São Sebastião & 5,96 & 7,56 & 4,58 & 2,73 & 3,79 & 1,62 & 1,93 \\
\hline Ithabela & 4,78 & 5,95 & 3,22 & 4,09 & 4,59 & 3,39 & 2,76 \\
\hline Litoral norte & 4,99 & 6,11 & 4,17 & 2,60 & 3,66 & 1,69 & 1,83 \\
\hline Baixada Santista & 3,27 & 3,09 & 3,54 & 1,58 & 2,18 & 0,71 & 1,36 \\
\hline Litoral sul & 3,25 & 3,31 & 3,13 & 3,37 & 2,65 & 4,14 & 4,25 \\
\hline
\end{tabular}

Fonte: IBGE.Censos Demográficos de 1991-2010.

Em Caraguatatuba, é clara a queda da participação do turismo apoiado na segunda residência. Entre os municípios litorâneos, as taxas de crescimento dos domicílios de uso ocasional em Caraguatatuba só não foram superiores às verificadas em Cubatão, Santos e São Vicente, áreas já densamente urbanizadas e integradas às dinâmicas metropolitanas. É importante ressaltar a centralidade de tais cidades em seus papéis tanto no processo industrial como na questão logística da região. Assim, Caraguatatuba cresce muito menos direcionada ao fortalecimento de suas características balneárias. Entretanto, esse vetor da economia ainda não pode ser desconsiderado, já que os domicílios de uso ocasional continuaram representando uma porcentagem elevada: 43\% do total de domicílios em 2010.

Esta mudança no perfil do crescimento urbano, deslocando-se do uso ocasional turístico para a busca por oportunidades de trabalho em um centro urbano dinâmico economicamente, resulta na ocupação e valorização de áreas distintas. Se a expansão turística se espalha pelos vários quilômetros da costa, não raro valorizando áreas pouco ocupadas, buscando espaços próximos ou com acesso facilitado às linhas da costa, a urbanização voltada para o processo de industrialização e metropolização concentra-se em áreas mais baratas, que têm sido, na história da urbanização brasileira, aquelas com restrições de uso. No caso do litoral de São Paulo, e especificamente Caraguatatuba, foco dessa análise, tais áreas de expansão são justamente as áreas de risco ambiental.

Além de ser o pivô de todas as transformações urbanas da região, Caraguatatuba possui um histórico de enfrentamento de desastres, cujo ápice foi a tromba d'água de 1967, um dos eventos mais intensos e significativos da história brasileira. Na época do evento, a cidade já era acostumada com os efeitos das fortes chuvas, com precipitações médias mensais chegando a $450 \mathrm{~mm}$. No entanto, em março daquele ano, as precipitações saturaram os medidores pluviométricos e causaram encharcamento das encostas, criando um cenário propício a deslizamentos de grandes proporções. Escarpas de serras deslizaram em uma área superior a $200 \mathrm{~km}^{2}$, cobrindo com lama, pedras e troncos mais de 2/3 das áreas urbanas e rurais do 
município, isolando a cidade. Os danos incluem aproximadamente a descida de 30 mil árvores do morro, de 5 mil troncos soterrando casas e destruindo parte da BR-6, desaparecimento de $23 \%$ das casas e 3 mil pessoas desabrigadas (20\% da população) (ABDALLA, 2004).

Além disso, o evento culminou no fim das atividades da Fazenda dos Ingleses, central para a economia local, encerrando o ciclo agrário. Isso alterou radicalmente as formas de viver em Caraguatatuba, que ainda era bastante dependente da atividade agrária. A cidade se reconstruiu, tomando outra direção. A alternativa seguida para a reconstrução da cidade e da autoestima da população foi o turismo. A desvalorização causada pelo evento de 1967 se tornou uma oportunidade para o primeiro grande movimento imobiliário na década de 1970 (ABDALLA, 2004).

Tal movimento indica que o processo de recuperação de desastres na cidade não foi simplesmente um retorno ao estado anterior. Ao contrário, o momento foi abordado como um estímulo ao crescimento de vetores econômicos até então pouco explorados, e a ocupação foi acelerada. É interessante e essencial notar que tal processo não é único. Pais e Elliot (2008) argumentam que a reconstrução de cidades nos EUA em função de tornados e furacões transforma os lugares, indo muito além da recuperação e incluindo também a expansão econômica devido à grande inserção de capitais para a reconstrução. Nesse processo muitas vezes a dinâmica imobiliária, dada a escassez de moradias pós-desastre, causa a elevação do preço dos aluguéis e, no curto prazo, inviabiliza a continuidade dos mais pobres no local. Porém, em um momento posterior, com a inserção de capitais de seguradoras (contratadas previamente pelos mais ricos, principalmente) e do próprio Estado, os locais crescem ainda mais intensamente, mas, em muitos casos, atraindo a parcela mais rica da população.

Felizmente, eventos com a intensidade da tromba d'água de 1967 não se repetiram na região de Caraguatatuba desde então. No entanto, a linha litorânea do sudeste brasileiro, intensamente urbanizada, passa anualmente por eventos extremos de chuva que destroem lugares, matam pessoas e deslocam populações. Em Caraguatatuba, a urbanização da última década potencializou a criação de novas áreas de risco, aumentando a população exposta a tais eventos.

Nesse cenário, passamos a uma análise mais profunda das áreas de risco em Caraguatatuba, cidade que, como visto, exerce um papel polarizador na região e que deverá ser intensificado no futuro próximo.

Recente levantamento da Unesp (2006) mapeou 18 áreas de risco no município, das quais 16 estão em áreas urbanas e apenas duas em rurais. Os perigos analisados são os escorregamentos (que ocorrem em encostas ou taludes) e os solapamentos (em margens de córregos), basicamente de um ponto de vista geológico-geotécnico. Destas 18 áreas, totalizando 49 setores censitários, apenas uma está em margens de córregos e as demais sob o risco de deslizamento.

Do ponto de vista legislativo, técnico e institucional, o relatório se destaca na maior compreensão dos riscos ambientais da cidade. Contudo, um quesito que consideramos essencial está em compreender a dinâmica social e demográfica desses setores e de 
seu entorno. Quais as condições de habitação em tais áreas? Qual é a evolução de suas populações ao longo do tempo? Nessa perspectiva, ainda pouco explorada no Brasil, relacionamos as áreas mapeadas pela Unesp e avaliamos a evolução da população e das residências em cada uma dessas áreas (Figura 2 e Tabela 5).

FIGURA 2

Áreas de risco

Município de Caraguatatuba - 2010

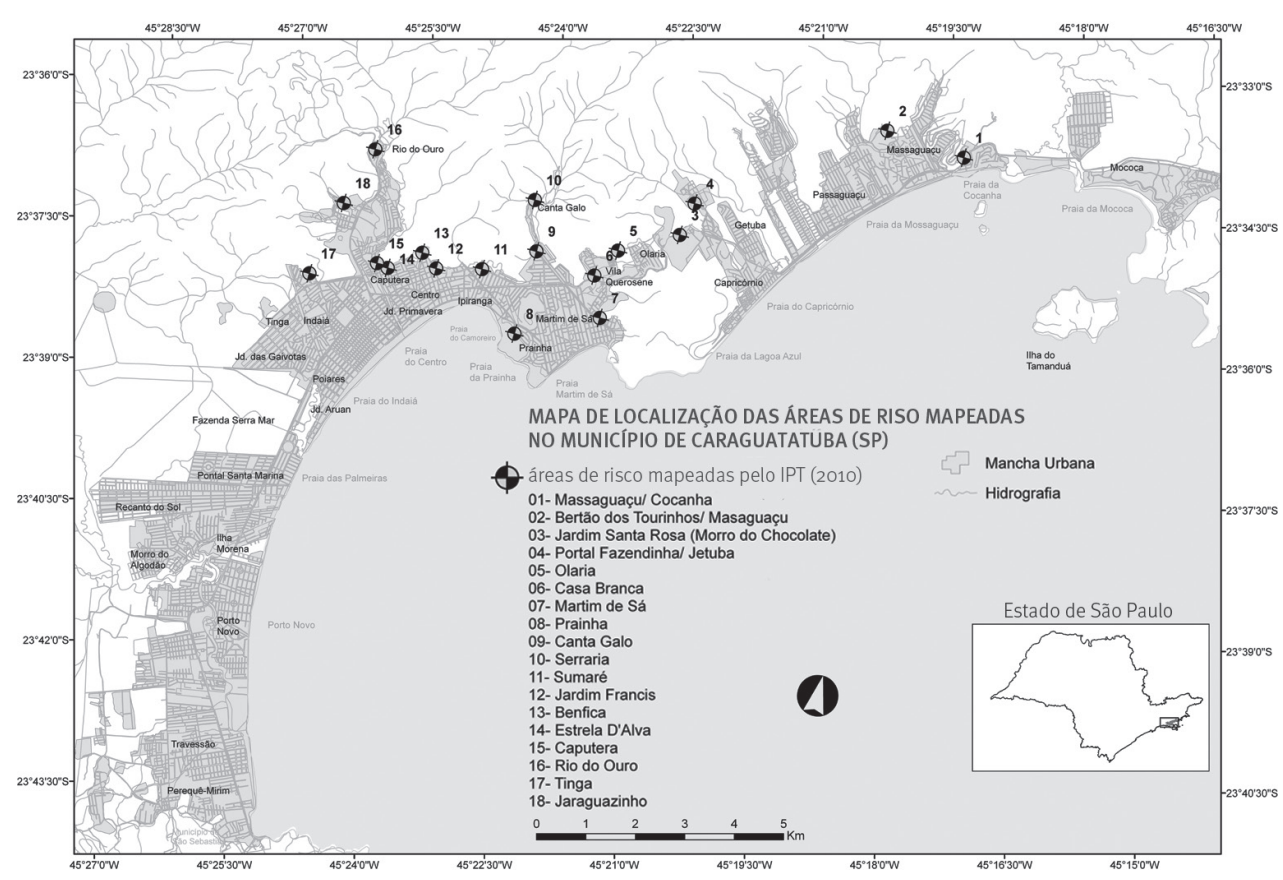

Fonte: Instituto de Pesquisas Tecnológicas - IPT (2010).

Metodologicamente, os dados em cada uma das áreas são os dos setores censitários urbanos localizados em um raio de até 50 metros do ponto relatado como área de risco no levantamento da Unesp (2006). Como dois pontos estão localizados em setores tidos como rurais, os mesmos não foram incluídos na análise.

Na maior parte dos casos, as taxas de crescimento da população em áreas de risco foram maiores do que as verificadas no município, superando, em alguns casos, $4 \%$ a.a. No geral, há relação entre o crescimento da população e dos números de domicílios, mas não se pode extrapolar tal tendência em todos os locais. Menor ainda é a relação entre esse crescimento e a dinâmica dos domicílios alugados. Em algumas localidades (Massaguaçu/ Cocanha e Tinga), o número de residências alugadas foi significativamente superior ao do crescimento populacional. 
TABELA 5

População e taxas de crescimento populacional e de domicílios, segundo áreas de risco Município de Caraguatatuba - 2000-2010

\begin{tabular}{|c|c|c|c|c|c|c|c|}
\hline \multirow{3}{*}{ Bairro /área de risco } & \multicolumn{2}{|c|}{ População } & \multicolumn{5}{|c|}{ Taxas de crescimento $2000 / 2010$ (\% a.a.) } \\
\hline & \multirow{2}{*}{2000} & \multirow{2}{*}{2010} & \multirow{2}{*}{ População } & \multicolumn{4}{|c|}{ Domicílios } \\
\hline & & & & Total & Próprios & Alugados & Cedidos \\
\hline Massaguaçu/Cocanha & 403 & 439 & 0,86 & 2,00 & 7,18 & 23,11 & $-3,27$ \\
\hline $\begin{array}{l}\text { Sertão dos Tourinhos/ } \\
\text { Massaguaçu }\end{array}$ & 776 & 1057 & 3,14 & 4,75 & 4,34 & 7,41 & 4,70 \\
\hline Portal Fazendinha/Jetuba & 901 & 896 & $-0,06$ & 0,45 & 0,69 & 3,63 & $-5,71$ \\
\hline Olaria/Casa Branca & 1.507 & 2.095 & 3,35 & 5,11 & 3,78 & 7,94 & 8,30 \\
\hline Martim de Sá & 991 & 1.454 & 3,91 & 5,24 & 6,32 & 13,39 & $-0,32$ \\
\hline Prainha & 536 & 803 & 4,13 & 5,49 & 8,67 & 10,11 & $-0,23$ \\
\hline Canta Galo & 657 & 1041 & 4,71 & 6,37 & 5,50 & 14,64 & $-1,95$ \\
\hline Sumaré & 1.246 & 1.610 & 2,60 & 3,77 & 4,52 & 5,88 & $-3,13$ \\
\hline Jardim Francis & 1.148 & 1.093 & $-0,49$ & 1,46 & 1,78 & 2,82 & $-5,08$ \\
\hline Benfica & 2.063 & 2.155 & 0,44 & 2,14 & 2,15 & 3,38 & $-2,90$ \\
\hline Estrela d'Alva & 658 & 978 & 4,04 & 4,97 & 3,65 & 8,55 & 2,26 \\
\hline Caputera & 2645 & 3319 & 2,30 & 3,94 & 2,91 & 6,16 & $-0,17$ \\
\hline Rio do Ouro & 1.187 & 1.363 & 1,39 & 3,24 & 3,05 & 4,88 & 2,76 \\
\hline Tinga & 887 & 1.133 & 2,48 & 4,46 & 3,85 & 12,31 & $-7,05$ \\
\hline Jaraguazinho & 851 & 962 & 1,23 & 2,46 & 2,52 & 5,03 & $-3,97$ \\
\hline Total/Média & 18.456 & 22.408 & 2,27 & 3,72 & 4,06 & 8,62 & $-1,05$ \\
\hline
\end{tabular}

Fonte: IBGE.Censos Demográficos de 2000 e 2010.

Vale ressaltar que em todos os lugares de risco, sem exceção, o aumento dos domicílios alugados foi superior ao crescimento da população, do total de domicílios e do total de domicílios próprios. De certa forma, essa é uma tendência em todo o município e pode ser observada na análise conjunta na Figura 3.

As áreas de risco apresentadas foram classificadas segundo o relatório técnico do IPT (2010). Suas categorias quanto às definições de risco são restritas e se baseiam em situações e processos em que há instabilidade de taludes, encostas e margens de córrego, que possam afetar as infraestruturas de moradias. As descrições para avaliação dos riscos são compostas por uma série de elementos geotécnicos, que combinados estabelecem o grau de risco para cada área.

Essas descrições são importantes, pois revelam a dimensão material da exposição a perigos dessa natureza. No entanto, há outras dimensões da vulnerabilidade da população desses municípios do litoral que ainda estão veladas ou pela própria demasiada ênfase à dimensão material do risco, ou ainda por não considerar as capacidades de resposta a riscos, que, inter-relacionados, são materiais, culturais, sociais e psicológicos. 
FIGURA 3

Taxas de crescimento da população, dos domicílios cedidos, alugados e próprios Município de Caraguatatuba - 2000/2010
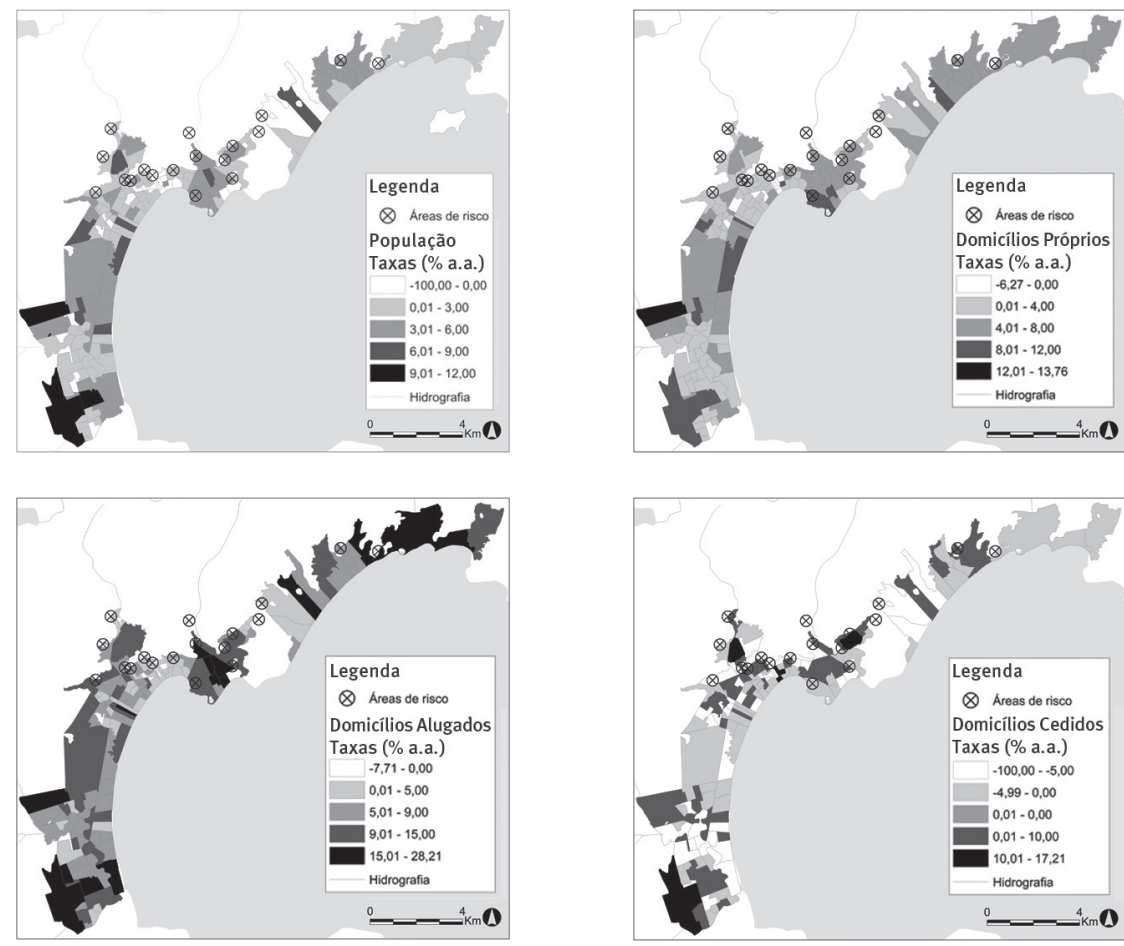

Fonte: Censos Demográficos 2000 e 2010 e de Unesp (2006).

Com a divulgação dos dados do Censo Demográfico 2010, pode-se analisar em conjunto a dinâmica de Caraguatatuba como um todo e das suas áreas de risco específicas, em termos da evolução da população e das residências nos locais. As principais tendências observadas nas áreas de risco foram:

- o crescimento da população foi relativamente menor nas áreas de risco em relação às regiões mais dinâmicas do município. No entanto, esse ainda foi positivo para a maioria dos casos;

- as taxas de crescimento das residências próprias foram medianas, ou seja, não se observaram os valores máximos e mínimos especificamente nessas áreas;

- o maior crescimento dos domicílios cedidos ocorreu nas áreas próximas aos riscos. Se para o total da cidade esse tipo de residência sofreu forte decréscimo, nessas localidades o mesmo foi positivo. Tal situação revela que, em muitos desses casos, a moradia é intensamente precária: não é própria nem alugada, foi cedida por um terceiro (temporária ou indefinidamente) e está localizada próxima ao risco. Nesse caso, é de se esperar um leque de opções muito pequeno para enfrentar os perigos;

- o crescimento dos domicílios alugados foi mediano, mas atingiu valores elevados nas áreas de risco. Nesse caso, há de se ressaltar que em toda a cidade as unidades aluga- 
das cresceram intensamente durante a última década. Mais uma vez, em muitos casos, os aluguéis nos lugares mais inseguros podem ter sido um atrativo às populações mais pobres em função dos menores valores e das possibilidades de moradia limitadas que se colocam a esses segmentos.

A elaboração de planos e gastos quanto às intervenções para "regularização" das áreas vulneráveis, normalmente pautados em medidas como impermeabilização do solo, muro de espera e de gabião, implantação de calhas, reaterro e conformação da encosta, retadulamento, demolição e reconstrução parcial da instalação e, em última instância, remoção da moradia, confere ações setoriais, sem, contudo, incorporar todo o contexto dinâmico no qual a vida dessas pessoas está inserida. Há de se balancear essas medidas (que, por ora, colaboram muito para o entendimento da vulnerabilidade dessas áreas), no sentido de assumir que as áreas de risco não são a mera desinformação ou falta de opção dessas pessoas em ocupar tais áreas, mas sim um fenômeno que está atrelado a todo processo de mudanças que esses municípios têm passado. É o próprio modelo de urbanização que está em questão.

\section{Urbanização de risco e resiliência}

O processo de urbanização do litoral norte paulista traz o risco em seu próprio processo constitutivo. A tendência deste novo período, que aponta para a metropolização da região, traz novas questões, novas demandas e novas características do processo de urbanização que ainda não foram pensadas ou previstas. Não é à toa que se considerem os municípios despreparados para enfrentar as mudanças ambientais consequentes, seja aquelas oriundas do modelo de desenvolvimento, seja as que estão sendo produzidas na escala global (FRANCINE JR.; GALLO JR.; OLIVATO, 2009).

Além de identificar as áreas de risco (o que tem sido feito a partir da recorrência dos eventos ou das características geológico-geomorfológicas), é necessário rediscutir o próprio modelo de urbanização. Nos planos de desenvolvimento, os municípios precisam incorporar a dimensão populacional para além do volume e encarar que, dentro da área limitada que têm para a ocupação, é preciso racionalizar o uso do espaço (MARTINE, 2007). Os desastres ambientais urbanos e as áreas de risco estão ligados a processos que vão além da realidade física, envolvendo a discussão do próprio sentido e modelo de urbanização (MARANDOLA JR., 2012).

Neste sentido, é necessário desfocar o crescimento populacional em si, enfatizando o modelo de urbanização e as políticas de desenvolvimento urbano. Uma demografia das mudanças climáticas necessita estudar as variáveis do metabolismo demográfico, não as taxas cruas do crescimento (OJIMA, 2011). Políticas de adaptação só serão possíveis a partir desta compreensão, contextualizada à produção do espaço urbano-regional e da geografia dos riscos, em várias escalas.

Se, de um lado, o turismo continua a ser um importante setor econômico, de outro, é preciso assumir uma perspectiva urbanística, de desenvolvimento urbano-regional para pensar o ordenamento territorial, para que se evite a expansão para as áreas de risco, 
ambientalmente comprometidas, e que os vazios urbanos e os domicílios para uso ocasional não gerem no seu reverso o aumento das áreas de risco.

O ponto principal da discussão é compreender que a metropolização, enquanto processo (LENCIONI, 2003), se instalou na região. A tendência para a próxima década é a intensificação da conurbação, já existente entre São Sebastião, Caraguatatuba e Ilhabela, mas que vai se intensificar e deve atingir Ubatuba. Mais do que uma conurbação física, que deverá se consolidar, a metropolização implica outros padrões de interações espaciais, que se refletem nas demandas por forma e usos urbanos.

O mais preocupante no caso do litoral norte e, em particular, de Caraguatatuba é a ausência da discussão ou preocupação com a adaptação e a resiliência. Estruturalmente, a cidade não está mais bem preparada para eventos como o de 1967 do que estava na época. Se hoje temos organizações civis como o GAAC (Grupo de Apoio Civil de Caraguatatuba) e uma sociedade civil mobilizada, em termos da lógica da expansão urbana a resiliência continua baixíssima, tanto estrutural quanto social.

É necessário observar que a resiliência é constitutiva de um processo, e que as atuais preocupações acerca da sua promoção, que a colocam sob um caráter normativo, devem ser relativizadas e encaradas a partir da dinâmica social e urbana atual, que, como o caso presente ilustra, é marcada pelo risco. Documentos como o Framework de Hyogo (criado pela ONU em 2005 para guiar o gerenciamento do risco de desastres), que estabelece como necessários o aumento do desenvolvimento e das capacidades em todos os níveis (especialmente no nível da comunidade), a criação de uma política de redução do risco dos desastres, a identificação e avaliação constante dos riscos e o uso do conhecimento, da inovação e da educação para construir uma cultura de segurança e resiliência (UNISDR, 2008), ainda estão distantes de serem efetivamente incorporados. Mais recentemente, dois documentos corroboram a tendência de reforço da resiliência: os relatórios Resilientpeople, resilientplanet:a future worthchoosing (UN, 2012) e Climate resilient cities (PRASAD et al., 2009). Ambos discutem a importância de implementação de sistemas de proteção social e da construção da resiliência como integrante do planejamento do desenvolvimento. Especificamente com relação às cidades, coloca-se que a resiliência é reflexo dos ativos das populações e dos serviços de infraestrutura fornecidos pela cidade onde vivem e pelas instituições, com ênfase na qualidade da governança urbana.

No Brasil, a discussão é bastante incipiente, sendo que a ênfase maior está na campanha coordenada pela Defesa Civil, intitulada “Construindo cidades resilientes: minha cidade está se preparando?” (DEFESA CIVIL NACIONAL, 2011). Tal campanha objetiva a implementação de cidades resilientes por meio de dez passos, incluindo as questões de uso e ocupação do solo. No entanto, consideramos que a atenção ao próprio modelo de desenvolvimento urbano é negligenciada, minimizando os efeitos de décadas de um processo de urbanização efetivado de forma desigual, o que coloca, por conseguinte, um obstáculo crucial na construção de cidades efetivamente resilientes. 
No caso específico de Caraguatatuba, se é possível identificar um grupo populacional exposto diretamente a esta urbanização de risco (os mais de 22 mil moradores nos setores adjacentes às 16 áreas de risco mapeadas), é preciso ir além, como sugerem Hardoy e Pandiella (2009), e promover a capacidade de tais pessoas de construir capacidades adaptativas e resiliências específicas, seja por capital social (redes de comunicação, alerta e solidariedade) e infraestruturas (adaptações e estruturas resistentes aos eventos), seja pela própria seguridade privada ou pública, acionada em casos específicos.

Estas opções não tornarão a urbanização resiliente, mas podem contribuir para diminuir a vulnerabilidade específica de lugares e grupos populacionais. Do ponto de vista político, no entanto, a arena de discussão é significativamente mais ampla, envolvendo a revisão do modelo de urbanização adotado e a composição de legislações específicas, assumindo as novas funções e demandas de infraestrutura que o modelo de desenvolvimento pautado na industrialização e nos grandes investimentos tem acarretado para a região.

\section{Referências}

AB'SÁBER, A. Os domínios de natureza no Brasil: potencialidades paisagísticas. 4ํㅡㄹ. ed. São Paulo: Ateliê Editorial, 2007.

ABDALLA, R. A. 0 processo de urbanização de Caraguatatuba - A gestão da cidade versus a gestão do balneário. Dissertação (Mestrado em Urbanismo). PUC-Campinas, Campinas, 2004.

ACSELRAD, H. Justiça ambiental e construção social do risco. Desenvolvimento e Meio Ambiente, V. 5, p. 49-60, 2002.

CASTRO, L. M. F. B.; MELLO, L. F. Mudança climática, riscos e vulnerabilidade: um estudo dos eventos ocorridos em 1967 e 1996 na planície litorânea de Caraguatatuba SP. CLIMEP. Climatologia e estudos da paisagem, v. 6, p. 22-43, 2012.

CONTI, J. B. Geografia e tropicalidade. Casa de Geografia de Sobral, v.12, n.1, p 47-58, 2010.

CARMO, R. L.; MARQUES, C.; MIRANDA, Z. A. I. Dinâmica demográfica, economia e ambiente na zona costeira de São Paulo. Campinas: Unicamp, 2012 (Textos Nepo, n. 63).

CARMO, R. L.; MARQUES, C. População em zonas costeiras e mudanças climáticas: redistribuição espacial e riscos. In: HOGAN, D. J.; MARANDOLA JR., E. (Orgs.). População e mudança climática: dimensões humanas das mudanças ambientais globais. Campinas: Nepo/UNFPA, 2009, p. 137-158.

CARMO, R. L.; NUNES, L. H. Climate change and human activities in Brazil with emphasis on the coastal zone. Terra e Didatica, v. 3, p. 40-45, 2008.

CRUZ, O. A Serra do Mar e o litoral na área de Caraguatatuba-SP: contribuição a geomorfologia litorânea tropical. São Paulo: USP, 1974.

DERSA. Nova Tamoios - Planalto: duplicação do trecho planalto. São Paulo: DER/DERSA, 2011.

DEFESA CIVIL NACIONAL. Construindo cidades resilientes: minha cidade está se preparando? Campanha Mundial de Redução de Desastres, 2011. Disponível em: 〈www.defesacivil.gov.br/ cidadesresilientes/pdf/Documento_Final.pdf>.

FRANCINE JR., R.; GALLO JR., H.; OLIVATO, D. O aquecimento global e suas implicações para a região do litoral norte de São Paulo: subsídios à gestão ambiental costeira. Leopoldianum, n. 96, p. 59-78, maio-agosto 2009. 
DI GIULIO, G. M.; FERREIRA, L. C. Governança do risco: uma proposta para lidar com riscos associados às mudanças climáticas e ambientais no nível local. In: VI ENCONTRO NACIONAL DA ANPPAS. Anais... Belém, 2012.

HARDOY, J.; PANDIELLA, G. Urban poverty and vulnerability to climate change in Latin America. Environment and Urbanization, v. 21, n. 1, p. 203-224, 2009.

HOGAN, D. População e mudanças ambientais globais. In: HOGAN, D. J.; MARANDOLA JR., E. (Orgs.). População e mudança climática: dimensões humanas das mudanças ambientais globais. Campinas: Nepo/UNFPA, 2009, p. 11-24.

. População, pobreza e poluição em Cubatão, São Paulo. In: MARTINE, G. (Org.). População, meio ambiente e desenvolvimento: verdades e contradições. Campinas: Ed. da Unicamp, 1993, p. 101-131.

HOGAN, D.; MARANDOLA JR., E.; OJIMA, R. População e ambiente: desafios à sustentabilidade. São Paulo: Blucher, 2010.

IPT - Instituto de Pesquisas Tecnológicas. Mapeamento de risco e parecer técnico. Caraguatatuba, 2010.

LENCIONI, S. Uma nova determinação do urbano: o desenvolvimento do processo de metropolização do espaço. In: CARLOS, A. F. A.; LEMOS, A. I. (Orgs.). Dilemas urbanos: novas abordagens sobre a cidade. São Paulo: Contexto, 2003.

MARANDOLA JR., E. Tangenciando a vulnerabilidade. In: HOGAN, D. J.; MARANDOLA JR., E. (Orgs.). População e mudança climática: dimensões humanas das mudanças ambientais globais. Campinas: Nepo/UNFPA, 2009, p. 29-52.

. Quatro razões para não falar sobre desastres ambientais urbanos. In: MARTINE, G. et al. (Orgs.). População e sustentabilidade na era das mudanças ambientais globais: contribuições para uma agenda brasileira. Belo Horizonte: Abep, 2012, p. 151-161.

MARANDOLA JR., E.; HOGAN, D. J. Vulnerabilidade do lugar vs. vulnerabilidade sociodemográfica: implicações metodológicas de uma velha questão. Revista Brasileira de Estudos de População, v. 26, n. 2, p. 161-181, 2009.

MARQUES, C. População e riscos às mudanças ambientais em zonas costeiras da Baixada Santista: um estudo sócio-demográfico sobre os municípios de Bertioga, Guarujá e São Vicente. Dissertação (Mestrado em Demografia) - Faculdade de Filosofia e Ciências Humanas, Universidade Estadual de Campinas, 2010.

MARTINE, G. O lugar do espaço na equação população/meio ambiente. Revista Brasileira de Estudos de População, v. 24, n. 2, 2007.

MODESTO, F. Populações em situações de risco ambiental em São Sebastião, Litoral Norte de São Paulo. Dissertação (Mestrado em Demografia) - Faculdade de Filosofia e Ciências Humanas, Universidade Estadual de Campinas, 2011.

MODESTO, F.; MARANDOLA JR., E. Populações em situação de risco ambiental e vulnerabilidade do lugar em São Sebastião, Litoral de São Paulo. Desenvolvimento e Meio Ambiente (UFPR), 2012. [aceito para publicação]

MONTEIRO, C. A. de F. O clima e a organização do espaço no estado de São Paulo: problemas e perspectivas. São Paulo: Universidade de São Paulo, Instituto de Geografia, 1976 (Série Teses e Monografias, n. 28).

MORAES, A. C. R. Contribuções para a gestão da zona costeira do Brasil: elementos para uma geografia do litoral brasileiro. São Paulo: Annablume, 2007. 
OJIMA, R. As dimensões demográficas das mudanças climáticas: cenários de mudança do clima e as tendências do crescimento populacional. Revista Brasileira de Estudos de População, v. 28, n. 2, p. 389-403, 2011.

PAIS, J. F.; ELLIOT, J. R. Places as recovery machines: vulnerability and neighborhood change after major hurricanes. Social Forces, v. 86, n. 4, p. 1415-1453, 2008.

PRASAD, N. et al. Climate-resilient cities: 2008 Primer. Washington, D. C.: International Bank for Reconstruction, The World Bank, 2008.

ROCHA, K. N. D. Relações entre a vulnerabilidade social e a fragilidade ambiental no litoral norte paulista: o caso dos municípios de Ilha Bela, São Sebastião, Caraguatatuba e Ubatuba. Dissertação (Mestrado em Geografia). Campinas: Unicamp, 2011.

SCHVASBERG, B. Tendências e problemas da urbanização contemporânea no Brasil. In: CASTRIOTA, L. B. (Org.). Urbanização brasileira: redescobertas. Belo Horizonte: C/ Arte, 2003, p. $43-63$.

UNESP. Elaboração de plano de redução de riscos da estância balneária de Caraguatatuba (SP). Vol.1, Funep, 2006.

UNISDR. Climate resilient cities: reducing vulnerabilities to climate change impacts and strengthening disaster risk management in East Asian cities, 2008.

VILLASCHI, J. Novas modalidades de urbanização e sua inserção regional: o condomínio Alphaville Lagoa dos Ingleses, Nova Lima-MG. In: CASTRIOTA, L. B. (Org.). Urbanização brasileira: redescobertas. Belo Horizonte: C/ Arte, 2003, p. 159-174.

\section{Abstract}

\section{Urban growth and areas of risk in of the state São Paulo North Coast}

Urban growth and sprawl bring with them hazards and risks that are expressed by the lack of adjustment and adherence of urban space production to the natural systems. This situation gets worse when the location itself is naturally vulnerable, as in the case of the North Coast of São Paulo state. This region experienced one of its decades of largest urban and economic growth, in the context of significant transformations associated to oil and gas exploration, the expansion of the port of São Sebastião, changes in touristic activities and the consolidation of urbanization, especially in Caraguatatuba, the center where most of the transformation began. After learning the results of the 2010 Census, it is the appropriate time to measure the intensity and how this growth occurred in the last decade, which was empirically observed, and its relations with hazards and vulnerability. If there is a relation between urbanization and risk, the tendency is that the deep and intense changes may have intensified and created new risk areas, as the urban sprawl reached naturally fragile areas. We have tried to identify the people who live or work in these areas, focusing on the new areas, starting from understanding the process of urbanization in the humid tropics and its consequences in terms of risk and vulnerability, focusing on the 2000 and 2010 census data.

Keywords: Urbanization. Climate change. Geography. Population and environment. 


\section{Resumen}

\section{Crecimiento urbano y áreas de riesgo en el litoral norte de São Paulo}

El crecimiento y la expansión urbana ocasionan, en su propio proceso constitutivo, riesgos y peligros que se expresan por medio de la falta de ajuste y adhesión de la producción del espacio urbano a los sistemas naturales. Esta situación se agrava cuando el propio sitio es naturalmente frágil, como es el caso de las áreas costeras del litoral norte de São Paulo. Esta región vivió una de sus décadas de mayor crecimiento urbano y económico en el marco de grandes transformaciones vinculadas a la explotación de gas y petróleo, a la expansión del puerto de São Sebastião, a los cambios en la actividad turística y a la consolidación de la urbanización, especialmente en Caraguatatuba, sede y polo irradiador de la mayor parte de las transformaciones. Divulgados los datos del Censo 2010, éste es un momento propicio para precisar la intensidad y las formas de dicho crecimiento en la última década, observándolo empíricamente, así como sus relaciones con los riesgos y la vulnerabilidad. Si hay una relación entre urbanización y riesgo, la tendencia es que los intensos cambios recientes profundizaron y crearon nuevas áreas de riesgo, mientras la expansión urbana avanza sobre áreas naturalmente frágiles. El presente estudio procura identificar a quienes viven o trabajan en estas áreas, concentrándose en las nuevas áreas a partir de una comprensión del proceso de urbanización en el trópico húmedo y sus consecuencias en lo que concierne a riesgos y vulnerabilidad, con un enfoque en los datos de los Censos de 2000 y 2010.

Palabras clave: Urbanización. Cambio climático. Geografía de los riesgos. Población y ambiente.

Recebido para publicação em 07/01/2012

Aceito para publicação em 08/07/2012 